\title{
A ÉTICA DA PESQUISA NA ERA DA AUTORIA Direito intelectual indígena, socialidade e invenção antropológica
}

\section{Oscar Calavia Sáez}

\section{Etimologia}

Os termos autoria e autoridade procedem de um mesmo étimo; são mais exatamente acepções tardiamente separadas de um mesmo termo. Em Vocabulário das instituiçôes indo-europeias, Benveniste dedica um verbete ao conjunto auctor-auctoritas, de onde procedem também augúrio e augusto: todos esses termos têm sua origem em augeo, "fazer crescer”. O conjunto alude, assim, à virtude fecundante de algumas ações, entre as quais poderiam se contar as do soberano. ${ }^{1}$ Mas esse vínculo entre $a u$ toridade e autor - embora o vocábulo pouco tenha mudado desde sua forma original - parece-nos já contraintuitivo. "Autoridade" ingressou no léxico político e, antes que à fecundidade, associa-se ao limite e ao controle, especialmente em derivados como autorizar ou autorização. A segunda continua

Artigo recebido em 03/02/2013

Aprovado em 07/08/2013 aludindo à criação, mas já secularizada e desprovida de sentido moral.

Não é difícil adivinhar que a especialização do significado de auctoritas se deu a partir do seu uso para designar a auctoritas das Sagradas Escrituras, que ainda vigora com certo relento antiquado. $\mathrm{O}$ que pode surpreender é que esse significado tenha prevalecido até tão tarde nas línguas latinas. Para lexicógrafos como Nebrija em $1494,{ }^{2}$ ou Covarrubias em 1611, "autoridade" é ainda o atributo de quem escreve, principalmente livros; o segundo refere-se também a qualidades morais como a "gravidade" ou a "eminência", sem aludir ainda a funções políticas. Foi apenas nos últimos quatro séculos que o campo da autoria e o da autoridade definiram seus limites. Ainda hoje, uma língua como o francês traduz autoria ou authorship por uma metáfora: paternité.

Mesmo depois de sua diferenciação, autoridade e autoria coincidem em marcar o limite de 
um campo relacional. A autoridade - à diferença do simples poder, que pode surgir e se impor desde fora - emerge de uma rede de relações em que o sujeito da autoridade conseguiu se situar como um vértice. Não haveria autoridade sem a rede, mas a rede está, digamos, recolhida nessa autoridade, e pode ser vista como se dela surgisse. De um modo muito semelhante, a autoria maneja um cúmulo de materiais e inspiraçôes prévios, mas o faz constituindo-se numa nova origem, numa fonte. $\mathrm{O}$ autor não é um simples intermediário, do mesmo modo que o sujeito com autoridade não é apenas a expressão de um desígnio da rede. Em ambos os casos, o sujeito é (provisoriamente, ilusoriamente?) dotado de uma força autônoma que, no caso da autoridade, é intransitiva, mas no caso da autoria remete a um objeto direto: a obra.

Antes da aparição desse objeto, a auctoritas (para evitar confusôes, usarei o termo latino quando aludir a esse sentido original não diferenciado) designa um fluxo intensivo em que o sujeito-autor se confunde com o que ele faz. A auctoritas aponta para uma potência, uma preeminência, mas não, note-se, para uma exclusividade. Depois, a autoria passa a existir e gravitar em volta de um objeto que ganhou uma existência independente: como o próprio objeto, torna-se extensa, e portanto definida, com limites. A autoria é exclusiva: uma obra é de um autor ou de outro. O que une o autor à obra não é mais a potência do autor, mas uma convenção jurídica: o direito autoral.

Provavelmente a cisão de auctoritas em autoridade e autoria é contemporânea do início da "galáxia Gutenberg”, quando surge o livro impresso, cuja autoria deve constar na ausência do autor. É frequente assinalar o início do copyright em legislações inglesas dos séculos XVII ou XVIII, mas a data pode ser provavelmente adiantada. Vejam-se as páginas iniciais de qualquer livro espanhol de inícios do século XVII: logo depois da folha de rosto com o título, o nome do autor, o emblema e a dedicatória a um personagem da aristocracia, encontramos o privilegio real, que garante ao autor a licença exclusiva durante dez anos para fazer imprimir sua obra, e ameaça os contraventores com fortes multas e, sobretudo, com o confisco das suas máquinas de imprimir. Aparece também a "Fé de Erratas", uma revisão de texto cujo interesse na época não é puramente editorial: trata-se de garantir que a obra impressa seja fiel ao manuscrito, responsabilizando plenamente ao autor daquilo que ele deu a público uma letra apenas pode fazer muita diferença em matéria de doutrina. E, enfim, está a censura, que certifica que na obra não há nada contrário à Fé ou à Moral. Autoria e autoridade aparecem lado a lado, mas já diferenciadas e encarnadas em sujeitos diferentes: o autor de um lado, os censores e patrocinadores de outro. O discurso sobre a propriedade intelectual costuma sublinhar apenas o primeiro aspecto, saudando o início de uma era de independência criativa e de relação direta do autor com o mercado; não costuma reparar no aparato de controle que surge junto com ele. Um pouco menos de ufanismo individualista, e a aparição do direito autoral pode ser vista como a possibilidade de alienar em favor de um terceiro a relação entre autor e obra. De fato, os detentores efetivos desses direitos não costumam ser autores, mas editores, empresários ou herdeiros

\section{Etnografia}

Passemos a um exemplo, tirado da minha própria pesquisa etnográfica (Calavia Sáez, 2006), que traz essa discussão para o foco contemporâneo deste artigo. Quando realizei meu trabalho de campo entre os Yaminawa ${ }^{3}$ e me interessei por suas narraçôes míticas, os shedipawó, havia consenso de que a pessoa mais habilitada para contá-los era o velho Clementino, a quem fui devidamente encaminhado. Ele se mostrou disposto a compartilhar seu saber sem maiores requisitos quanto às condições em que a pesquisa se faria, ou mesmo à retribuição que lhe corresponderia por isso. ${ }^{4}$ Clementino narrava os shedipawó de modo eficaz, de fato mais breve que o de outros narradores: menos digressivo, mais dinâmico, mais encenado - uma encenação verbal na qual eram de primeira importância coisas como o assobio das flechas, o efeito de distância das vozes. A autoridade de Clementino residia, aparentemente, na sua performance mais do que na quantidade de informação que ele guardava ou transmitia. Ele não ocultava (nem precisava explicitar) o fato de ter 
aprendido os shedipawó por intermédio de outros; nem, com certeza, impedia que as mesmas narraçôes, às vezes com diferenças substanciais, fossem enunciadas por outros. A mitologia yaminawa é consideravelmente democrática, ou mesmo anárquica: todo Yaminawa era um narrador em potencial, e quase todo Yaminawa, incluindo as crianças, era um narrador em ato se a ocasião se apresentava. ${ }^{5}$ Mas era a autoridade de Clementino, sua força como narrador, o que fazia existir esses relatos na sua máxima expressão.

A essa disposiçāoo geral para narrar havia apenas uma exceção. Clementino tinha uma contrafigura, o velho Sebastião, que segundo muitos já fora xamã, ou para usar o termo vernáculo, koshuiti termo que supunha descartar os graus mais altos de conhecimento xamânico, que incluiriam potências xamânicas mais agressivas. Mesmo nesse grau inferior, Sebastião - dizia-se - não era muito ativo: segundo minhas primeiras informações, ele estaria já aposentado. Não tardei em ter fartas evidências de que essa "aposentadoria" não passava de um comentário malevolente: o velho Sebastião realizava sessōes de shori (ayahuasca) na sua casa e era frequentemente procurado por uma clientela externa, de outros índios ou de brancos, que acudiam a ele para remediar todo tipo de aflições. Mas aquela desqualificação inicial encontrava eco em suas próprias declarações: Sebastião declarava indefectivelmente não saber nada. Nem de xamanismo, nem de velhos rituais, nem de desenhos, nem de paramentos, nem sequer de narraçōes que até as crianças sabiam contar. Não porque fosse um sujeito arredio: era um homem gentil e acolhedor, tão dado à conversa como qualquer outro. Mas sua negativa não se restringia a mim, pesquisador estrangeiro. Parentes muito próximos o acusavam de sovinice e, por vezes, aproveitando uma ausência do dono, mostraram-me furtivamente os itens da cultura tradicional, absolutamente ausentes nas outras casas, que o velho koshuiti guardava escondidos entre as palhas do telhado: coisas como o único conjunto de arco-e-flechas que vi entre eles. Em alguma mala chaveada, disseram-me, ele tinha mesmo alguns baité -tocados tradicionais feitos de casca de embira ou pele de animais - que só ele sabia fazer. $\mathrm{Na}$ verdade, toda aquela "cultura" yaminawa que eu tinha procurado em vão estava guardada nos cantinhos da casa daquele xamã aposentado que "não sabia nada". Essa "ignorância" me foi mais tarde matizada pelo próprio koshuiti durante um encontro casual numa praia do rio Acre - ele voltava à aldeia, eu voltava à cidade - onde compartilhamos um peixe assado. Naquele momento ele reconheceu que de fato sabia algumas coisas, mas seu saber tinha um preço que, na sua opinião, eu não poderia pagar. Com razão: como a seguir me explicou, recentemente ele tinha recebido uma espingarda nova em troca da gravação de um canto xamânico. Demasiado para um pesquisador com recursos limitados, que preferia fabricar sua própria objetivação da cultura yaminawa em lugar de pagar o preço devido pela objetivação de outrem ${ }^{6}$ (ou seja, pela "cultura" yaminawa, no sentido que um artigo de Manuela Carneiro da Cunha (2009) introduziu no léxico habitual da profissão). Sebastião tinha uma noção muito exata do preço das coisas no mundo dos brancos, e na mesma conversa em que me falou do preço do seu saber quis se informar do preço de utensílios de gravação e do número e preço das pilhas e fitas que precisaria para usar o gravador.

Toda essa reticência e essa sonegação do saber me pareceram, na época, impedimentos graves à minha pesquisa. Com o tempo, aprendi que se tratava de uma lição cujo alcance se ampliou desde então num sentido que o velho Sebastião já captava com lucidez.

Os Yaminawa, naquela época - essa situação pode ter mudado substantivamente há muito pou$\mathrm{co}^{7}$ - sofriam por não investir na noção de "cultura”. Outros grupos indígenas acreanos a usavam já com extrema eficiência: os Ashaninka, os Kaxinawá e, cada vez mais, os Yawanawá, de língua e história muito próximas. A "cultura" começava a ser uma variável no jogo político acreano, que nos anos seguintes incrementaria sua importância. Mas nesse denominador comum abriam-se profundas diferenças entre as diversas etnias dependendo do lugar que cada uma delas dava a essa "cultura". Ashaninka, Kaxinawá, Yawanawa e Yaminawa se comportavam nesse quesito de modo muito diverso: a "cultura", essa objetivação de si dirigida ao outro, podia se apresentar sobreposta, justaposta, até oposta à pratica cotidiana. No caso Yaminawa, 
qualquer tentativa de manifestação da "cultura" era afogada por outros interesses. Depois de abandonar sua cerâmica, sua pintura corporal, seus rituais e seus arcos em favor de itens tomados de empréstimo ao mundo dos brancos, os Yaminawa se mostravam inacessíveis a toda integração na arena política multicultural do estado do Acre, que exigia a exibição de uma "cultura" própria. Os projetos de desenvolvimento - sustentável ou não - ou de resgate cultural naufragavam indefectivelmente entre eles, e o diagnóstico mais comum dessa situação apontava motivos muito clastreanos: sua instabilidade, seu "nomadismo" e sua indisciplina. Cada vez que chamados pelos indigenistas e pelo movimento indígena a refletir sobre suas dificuldades, os Yaminawa faziam votos, sem dúvida sinceros, de se comportar doravante; de respeitar seus chefes e de permanecer na sua aldeia, circunstâncias necessárias para que pudesse se desenvolver um adequado resgate da sua "cultura”. Quietos lá na aldeia, voltariam a produzir cerâmica, rituais e desenhos nas faces, e a viver como "verdadeiros índios". Mas pouco depois dessas boas intençôes, os Yaminawa voltavam a girar no seu círculo já conhecido: cisões, conflitos internos, troca de lideranças e perambulação constante nas cidades do Acre. Nada de "cultura”, mas quiçá muito dessa "cultura ameríndia" que os etnólogos têm caraterizado repetidamente com termos como inconstância ou anarquismo.

Clementino, com todo o seu prestígio, estava longe de ser rico ou poderoso: sua casa e seus roçados eram muito modestos, e sua intervenção política, mínima. No entanto, era o único habitante da terra indígena com o qual todos os outros reconheciam elos de parentesco, e isso mesmo que sua descendência direta e seu grupo familiar imediato fossem muito restritos. A autoridade de Clementino como narrador de mitos identificava-se com essa relação difusa, mas efetiva, que lhe unia a todos; quem sabe em outros tempos isso teria o alçado a uma chefia efetiva, mas para além do pouco interesse de Clementino na política o poder já estava na época concentrado em mãos de homens mais jovens, com um trânsito considerável no mundo dos brancos, figuras que em comparação com ele - um velho monolíngue, magro e provido de todos seus dentes - apareciam marcadamente "mestiças", na fala, nos interesses e na deterioração corporal por causa do consumo de macarrão e açúcar.

A reticência do velho Sebastiāo, por seu lado, ia além dessa prudência que o feiticeiro precisava para sobreviver. Negar sua autoridade era, para ele, uma condição necessária para reivindicar propriedade intelectual e retribuição monetária. Sebastião compreendia perfeitamente esse aparente paradoxo de que a auctoritas seja um empecilho para reter o direito autoral. Afirmar a auctoritas equivaleria exibi-la, e portanto compartilhá-la: reservar-se direitos passava por ocultar, sovinar, negar; atitudes que não são alheias à ética de um xamã. Isso o contrapunha aos jovens políticos, já prontos para reivindicarem-se como administradores da "cultura" sem as reticências de quem de fato a possui.

O modo mais expedito de objetivar uma "cultura” é que ela desapareça do cotidiano: ou seja, que mais ninguém a produza e a prodigue com auctoritas. A partir de então, o campo fica livre para a autoria, que pode ser reivindicada pelos indivíduos em proveito próprio, ou pelos líderes em nome da comunidade.

\section{Ética}

A antropologia crítica pós-moderna, tal como ela se apresentou a partir do célebre Writing cultures (Clifford e Marcus, 1986), executou um ataque frontal à noção de autoridade etnográfica e uma reivindicação igualmente marcada da autoria. A autoria do nativo, é claro, mas também a autoria do etnógrafo. Para cada um deles essa autoria vinha a ser coisa muito diferente. No caso do nativo, o reconhecimento de um direito até então negado: a emergência da sua condição de sujeito, de pensador, de inventor, a inscrição do seu nome na capa dos livros, a sua passagem de "informante" para "interlocutor" ou "mentor" ou "coautor". Pelo contrário, o etnógrafo, virando autor, perdia o que outros, especialmente o nativo, ganhavam. Reconhecer sua autoria significa, essencialmente, relativizá-lo e limitá-lo: ele é autor, nem mais nem menos autor que qualquer outro que se ocupe dessa mesma realidade; ele é autor, a sua obra é uma visão da realidade, não $o$ desvendamento da realidade. 
Não houve, que eu saiba, uma reflexão sobre as estreitas conexões entre a autoria que se afirmava e a autoridade que se negava: a noção primitiva de auctoritas não estava mais em foco. Mas a crítica pós-moderna gerou um persistente mal-estar no seio de uma ciência cujo único pesar, até a data, era o de nunca alcançar os padrões de teoria e método das ciências naturais. E isso porque, se o conceito de autoria surgiu em seu momento ligado à existência de objetos (as obras) tangíveis, a crítica pós-moderna colocou em primeiro plano a autoria, enquanto tirava de cena o objeto. Em particular, aquele que tinha sido o objeto predileto da antropologia: a cultura. A substantividade, a tangibilidade ou a efetividade dessa cultura tinham desmanchado no ar. Com efeito, essa antropologia crítica surge da interpretação das culturas, ao modo de Clifford Geertz (1973), e não da invenção da cultura, ao modo de Roy Wagner (2010). Os livros que ambos os autores publicaram em datas muito próximas coincidiam em refutar o paradigma da antropologia modernista, ou seja, a possibilidade de que a pesquisa desvendasse de algum modo universal e inequívoco seu objeto, mas o fizeram de modos opostos. Wagner postulava a produtividade humana, que dá lugar a um constante exercício de invenção e contrainvenção, mutável porém efetivo e eficiente, que criava para os humanos a realidade no seu conjunto - como cultura e como natureza. Geertz, em contrapartida, se refugiava na hermenêutica, que passava a ocupar todo o espaço das ciências humanas, deixando de fora a natureza, talvez ainda ao alcance de outras ciências.

A alternativa de Wagner ficou numa posição marginal; a de Geertz se tornou hegemônica: a crítica pós-moderna culminou essa desontologização das ciências humanas (trataremos disso mais adiante) que já ia se gestando desde o início da idade moderna.

Sem um objeto decisivo, a autoria tornava-se mais uma condição intransitiva; sem ele, os autores ficam a confrontar suas representações, suas teorias ou seus métodos, e como a crise alcança também esses elementos, ficam a confrontar-se como sujeitos, esgrimindo a legitimidade que lhes assiste, que pode vir do prestígio da sua instituição, do número e do impacto de suas publicaçōes, ou da excelên- cia ética do seu modo de pesquisar. A preocupação pela ética e a cultura da avaliação, embora superficialmente opostas, coincidem numa mesma conjuntura. ${ }^{?}$

Os nativos, cuja autoria acabava de ser proclamada, tinham sido convidados a um final de festa. Repete-se uma e outra vez que o conhecimento nativo tem o mesmo valor e a mesma dignidade que o conhecimento científico, quando não mais está claro em que consiste o valor e a dignidade deste.

\section{Aspas}

Mas ao mesmo tempo em que as ciências humanas se desontologizavam e a avaliação invadia os terrenos da epistemologia, a cultura dos nativos seguia um caminho há muito tempo frequentado na metrópole, objetivando-se em forma de "cultura", objetificada, armazenável, inventariável e passível de direitos autorais. É como se os antropólogos, tradicionais portadores e difusores do conceito de cultura, tivessem se encontrado de surpresa, um bom dia, com essas aspas.

Para o etnógrafo, essa objetivação tem uma utilidade imprevista, porque transforma o mal- estar difuso da etnografia ("Por que a minha interpretação em lugar ou ao lado, ou sob a interpretação deles?") num problema concreto: a pesquisa pode ser um roubo de saberes, fundamentalmente de saberes que podem levar aspas. E com essa definição do delito aparece a possibilidade de evitá-lo ou, se for o caso, de expiá-lo: a autoria, o reconhecimento e a regulação da autoria vêm se transformando no cerne da ética da pesquisa antropológica. Trata-se de identificar a autoria, de não se sobrepor a ela, de demarcar seus limites, de não violá-los; de estabelecer o equilíbrio entre um sistema de conhecimento, o do mundo do antropólogo, armado com livros impressos, patentes, copyrights e trademarks, e outro em que essas formas não existem. O contencioso, é claro, não se limitava mais às relações entre o etnógrafo e o nativo, abrangendo um campo muito mais amplo em que o antropólogo podia se redimir de suas faltas anteriores labutando pelos direitos intelectuais indígenas contra empresas ou museus. 
Na versão mais divulgada, trata-se de lutar pela definição de direitos intelectuais coletivos: apenas estes direitos coletivos, e não os individuais que são o padrão do direito ocidental, seriam capazes de recolher a autoria dos nativos. Isso não passa de resumo rudimentar de uma reflexão muito mais complexa que há anos sendo desenvolvida: por exemplo Brown (1998) além do já citado texto de Carneiro da Cunha. Mas, como anota esta última autora, os argumentos contra o senso comum raras vezes ganham batalhas, e as militâncias vêm se apoiando precisamente nessa súmula que, por inexata que seja, resulta de fácil compreensão.

Segundo o senso comum ocidental, o direito intelectual é uma consequência e também uma garantia da criação: é um bem inequívoco, que não duvidaríamos em oferecer a outros povos, mesmo que não faça parte da sua tradição, e bastaria encontrar modos de fazê-lo se enraizar nela. Nesse mesmo senso comum, a noção de direito autoral ou direito intelectual vem sendo substituída pela de direito de propriedade intelectual, e isso acontece como se esse último termo fosse apenas uma versão mais exata dos anteriores, e não um termo novo com valores muito diferentes. O senso comum, de novo, entende que o principal obstáculo para a defesa de direitos de propriedade intelectual indígena reside na inexistência de um conceito de propriedade privada.

As aporias interculturais resolvem-se, então, com equívocos de tradução. Os nativos escolhem o termo propriedade intelectual para traduzir suas relaçōes com a "cultura”, enquanto os "não nativos" escolhem o coletivo como tradução de tudo aquilo que não se adéqua ao regime individualista da sua economia.

No meio dos nativos, diz-se, faltam noções de direito intelectual, o que nada teria de surpreendente já que faltam, também, noções claras de propriedade material, que na sequência evolutiva seriam o antecedente e o modelo das outras. Ora, os nativos - um pouco por toda a parte, mas muito acintosamente no Brasil - continuam firmemente associados à ideia de comunismo primitivo, que já lhes atribuíram os humanistas do século XVI e vem sendo constantemente atualizada: não conhecem, de toda evidência, a propriedade privada da terra, da floresta ou dos rios, e pouco percebem a propriedade privada dos objetos de consumo, que são tradicionalmente perecíveis e instáveis. Que possibilidade haveria de que imaginassem uma propriedade da sua "cultura" que não fosse coletiva?

Todo esse argumento, tantas vezes repetido, continua ignorando uma evidência etnográfica que nada tem de esotérico. Nessas aldeias onde a noção de propriedade de um pedaço de terra ou mesmo de uma canoa é fluida ou porosa, o direito intelectual existe, e muito: decerto não esperou que a propriedade material lhe fornecesse um modelo. As questões de direito intelectual são especialmente dramáticas, como tentamos demonstrar alhures (Calavia Sáez, Naveira e Gil, 2003) para o caso Pano, que decerto não abrange a totalidade dos regimes de propriedade possíveis, mas mostra a extensão e a importância dos equívocos antes aludidos. Para começar, o conhecimento aparece quase que invariavelmente entendido como um bem chegado do exterior, conquistado pela força ou pela astúcia, ou bem oferecido por seres - animais, via de regra - que nunca obtêm a retribuição devida à sua generosidade. Os cultivares são roubados da casa de Yuwasidawa, o Sovina, que nesse mesmo ato é morto e esquartejado pelos assaltantes. Os métodos de cultivo são doados pelo esquilo, que também é vítima da malevolência humana e se afasta dela não sem antes se vingar. Os saberes relativos ao sexo e ao parto são devidos, respectivamente, ao macaco-prego e ao rato, que de modo algum recebem por isso a consideração merecida. $\mathrm{O}$ conhecimento da ayahuasca procede da sucuri, como conta outra história com desfecho trágico. Longe do conjunto Pano, é isso mesmo o que acontece no roubo do fogo de cozinha, patrimônio do jaguar, que é um dos pontos de partida de $O$ cru e o cozido de Lévi-Strauss. Mitos, sim, que têm correlato muito estreito na prática. As histórias de vida dos xamãs Pano (continuo me referindo ao nosso texto de 2003) mostram que a transmissão de conhecimento raramente se dá de modo automático, seguindo vias genealógicas ou de relevo de geraçôes. É objeto de uma dura negociação: os aprendizados xamânicos custam caro, ou devem ser roubados, por exemplo, espionando atrás da parede. O ladrão de saber, aliás, não é menos sábio por ser ladrão: como pode- 
ria sê-lo, se está a repetir o feito de um ladrão mítico? Mesmo na transmissão mais direta e regular de pais a filhos, ou de velhos a jovens, o dom do saber exige retribuiçôes eventualmente muito pesadas. E há, é claro, triunfos finais da sovinice, quando o pai, último elo da linha de transmissão do saber dos antigos, morre sem tê-lo transmitido - uma contingência relativamente comum; castigo do desinteresse ou da desobediência dos seus descendentes, porque o interesse deveria ter-se demonstrado com uma maior disposição a obedecer, a trabalhar na roça do pai, a morar na casa dele.

Ou seja, não há uma autoria no sentido de produção original a partir do nada e de direitos associados a essa produção. Vemos o saber trocando de mãos, sem que nunca se apresente o momento em que ele foi absolutamente originado. Há, sim, uma auctoritas associada a esses saberes, que a cada momento é afirmada, retribuída ou desafiada. Quando é desafiada com sucesso no contexto dos mitos, mudam as relações entre o auctor e seus usurpadores: o jaguar passa a comer cru e evitará ou matará os humanos que roubaram seu fogo. E na transmissão do saber entre humanos acontece algo parecido: cabe retribuir a auctoritas do mestre com serviços concretos ou com uma subordinação geral, mas também cabe usar a violência ou o engano, $\mathrm{e}$ suplantar essa auctoritas pela própria. A transmissão de saberes não é, digamos, como o fluxo de um rio que escoa naturalmente ao longo de um declive, mas como o fluxo de um sistema de irrigação que ordena o terreno ou, para ser mais exato, o cria. Um rio que não precisa fluir sempre, e pode deixar de fazê-lo. O conhecimento - seja ecológico, técnico, ritual etc. - é a sustância de que são feitas as relaçōes. Essa troca de cônjuges, bens e palavras que, segundo a famosa fórmula lévi-straussiana, constituem os grupos é também, e acintosamente, uma troca de saberes (associados aos bens, às palavras ou até aos cônjuges) que sustenta as relaçōes ou, mais exatamente, contribui para constituí-las. Em outras palavras, é um equívoco grave supor que faltam, fora do universo individualista euro-americano, noçôes de direito autoral. O direito autoral está ali, já faz muito tempo: é outro nome da estrutura social, ou da socialidade, para usar um termo mais adequado à sua elasticidade.
Postular o reconhecimento desses direitos cai num paradoxo eventualmente nocivo. Como já assinalou Marilyn Strathern (1999), tornar a "cultura" objeto de proteção e de direito supõe, de um lado, superar uma dicotomia que, entre nós, separa o social da tecnologia, da arte ou da ciência. Para nós, esses três domínios, produtores por excelência de direito autoral, estão à margem da vida social como tal, sendo por isso capazes de gerar direitos individuais: é o autor que pertence à sociedade, não as suas descobertas, seus romances ou suas músicas. Mas, é claro, não entenderemos a arte, a tecnologia ou a ciência indígena se quisermos encontrar entre "eles" esse mesmo divisor. Rituais, layouts de aldeias, sistemas de manejo ambiental ou práticas xamânicas estão embutidos na vida social, e são inseparáveis dela - são vida social. Prescindamos, assim, de uma dicotomia fora de lugar; e nesse momento já estaremos prestes, diz Strathern, a restaurar a dicotomia por outro lado. Porque proteger os saberes e reivindicar sua retribuição é outro modo de retirá-los da malha habitual em que se inserem, para outorgar-lhes um tipo de retribuição que não é mais a que até lá recebiam. Tudo isso que antes estava entremeado com as relaçôes sociais e as práticas quotidianas se transforma no "patrimônio" de uma "sociedade", mesmo que a relação entre esse objeto e esse sujeito coletivo e tudo o que preexistia a eles esteja longe de ser óbvia.

A distinção entre relaçôes sociais e sociedade não é bizantina, assim como a distinção entre cultura e patrimônio. É que patrimônio e sociedade são objetos muito reais e, sobretudo, novos. Acabam de aparecer, justapondo-se à realidade anterior. Não são apenas interpretaçôes ou arranjos novos da realidade que lá já estava, têm outros referentes. Os administradores do patrimônio coletivo não são, via de regra, os mesmos sujeitos que antes serviam de nós à rede social, os velhos detentores da autoridade. Para que seja possível uma retribuição externa da autoria indígena, ela deve ser extraída ou abstraída de um contexto onde a sua retribuição era inseparável da autoridade que ela sustentava.

Nesse ponto podemos entender as ocultações do xamã Yaminawa. A constituição de um patrimônio cultural tem consequências muito diferentes caso se aplique a elementos já de algum modo 
caducados, afastados do uso quotidiano, ou a bens ainda em circulação e com um valor de uso comum. O dilema nada tem de exótico: sabemos bem da diferença entre tombar uma igreja, ou um palácio vazio, para que representem a nossa "cultura" aos olhos do mundo - que pagará por desfrutá-la e tombar um bairro habitado, com seus costumes, atividades econômicas e rituais tradicionais. A constituição de uma autoria e de uma propriedade coletivas sobre a "cultura" já segregada tem escassos inconvenientes, mas essa situação é incomum entre povos que não tem meios de conservar peças arqueológicas, e onde quase todo o suscetível de se tornar "cultura" é ainda de uso corriqueiro. A "cultura" é formada, com muita frequência, de elementos sobre os que se fundamenta uma autoridade perfeitamente viva, e por isso a pretensão de extraí-los das trocas sociais para negociar com eles uma retribuição coletiva pode ser, no pior dos casos, fonte de infindáveis conflitos.

Geraldo Andrello refere-se a isso quando narra as discussões entre os autores da coleção Historiadores do Rio Negro e os juristas que assessoravam seu projeto editorial. Os juristas preocupavam-se, sobretudo, pela autoria e pelos direitos intelectuais vinculados a ela: tratava-se de salvaguardar um patrimônio étnico da eventual cobiça da indústria cultural. Os autores estavam interessados, em contrapartida, na auctoritas que se exerceria na difusão de suas histórias, uma auctoritas local (cada livro postula um cânone da hierarquia rio-negrina entre clâs) e uma auctoritas global, pois os livros no seu conjunto mostram que, mesmo tendo perdido seus rituais e sua cultura material, os Tukano continuam a enunciar uma tradição própria. $\mathrm{O}$ caso do rio Negro é interessante no melhor dos sentidos, porque a pesquisa de juristas e antropólogos (cf. Instituto Socioambiental, 2009) se estendeu por um vasto número de projetos com o cuidado de não induzir automaticamente uma tradução proprietária $^{10}$ das diversas preocupaçóes dos nativos acerca do destino do seu saber. Os problemas de autoria, ou a tensão entre autoria e autoridade, podem dar lugar a conflitos abertos, como os que Carneiro da Cunha narra a respeito do "veneno de sapo" ou das sementes Krahó, cuja autoria reivindicam múltiplos sujeitos exteriores ou interiores às sociedades que pretendiam obter a sua titularidade. Ou como o que cercou os registros videográficos que Divino Tserewahu e outros autores fizeram dos rituais xavante (Gonçalves, 2012). Neste caso, a produção de materializações duráveis - vídeos, registros sonoros, fotografias, textos - de um saber que dá sustância concreta a relações é um presente ambíguo para aqueles cujo lugar social é determinado pela posse desse saber. Certo, os velhos estão morrendo e com eles morre o conhecimento tradicional: o registro dessa "cultura" é um benefício indiscutível para a sociedade. Apenas, como acabamos de dizer, essa "sociedade", cujos direitos são assim acautelados, é uma realidade nova, não totalmente alheia, mas suscetível de uma gestão diferente da que até o momento se dava entre os sujeitos sociais. A possibilidade de que os velhos morram levando consigo o saber ancestral não é um infortúnio chegado junto com a civilização dos brancos: foi sempre um fator constituinte do próprio sistema tradicional de saberes: a possibilidade de não transmitir era o que dava seu poder aos sabedores, e o reconhecimento da autoria pode ser uma fraca compensação pela perda dessa autoridade. ${ }^{11}$

Os projetos de resgate cultural, de constituição ou preservação do patrimônio, podem ser muito benéficos ou muito conflituosos, mas são, sem dúvida, produtivos. Deixam algo que não existia antes, demonstrando com isso, precisamente, a auctoritas da pesquisa encarnada nesses projetos.

\section{O mal-estar}

Voltamos, assim, ao ponto em que deixamos a questão páginas atrás. A desaparição do objeto tem criado, ou tem dado vida longa e profunda, a um mal-estar que, de um modo mais ou menos patente, gravita sobre a pesquisa etnográfica. Desaparecido o objeto, toda a ênfase pesa sobre os sujeitos da pesquisa e as relações que se estabelecem entre eles. Se o pesquisador elabora à margem da voz indígena, seu trabalho avança num terreno dúbio, talvez ilegítimo. Caso se circunscreva a ela, torna-se supérfluo: esses nativos não têm já uma voz própria? Não é cada vez mais frequente a demanda de que sejam eles mesmos que compareçam a falar de si? 
Em que a pesquisa poderia contribuir a esta voz, salvo com o endosso de uma ciência que já carece de fontes próprias de legitimidade? A crítica pós-moderna extraiu da má consciência da profissão todas as consequências possíveis, menos a mais óbvia: abolir-se.

Um etnógrafo iniciante pode se perguntar para que seguir uma via de pesquisa situada entre a ilegitimidade e a redundância. Isso seria um resumo excessivamente pessimista da situação, mas seu perfil aparece claro nesse discurso do nativo que costuma ser produzido nos momentos iniciais da pesquisa. O nativo diz algo assim como "a nossa comunidade já está cansada de pesquisa; chega um pesquisador, e mais um, e mais um, leva todo o nosso conhecimento de valor e nunca dá um retorno para nós; somos nós os que devemos falar de nossa cultura". A essa reclamação, o pesquisador não tem para responder nada que não seja um eco: de fato, esse exórdio é com frequência anotado com orgulho nas etnografias, quem sabe sugerindo nas entrelinhas que neste caso tudo foi diferente.

Mas esse discurso tem muito mais de contrato que de avaliação. Muito mais do que estabelecer um juízo sobre a conduta dos pesquisadores anteriores - um juízo que flutua amplamente -, ele estabelece os princípios de uma negociação. De fato, essa revolta do nativo não tem sido o ponto final das relações de pesquisa, mas, pelo contrário, o lema de sua expansão: cada vez mais os pesquisadores (não necessariamente antropólogos, nem universitários) tornam-se um elemento relevante da política étnica.

Se anteriormente chamamos a atenção para o paradoxo de separar o saber como patrimônio, algo parecido poderia se dizer da ética da pesquisa. $\mathrm{O}$ retorno de uma pesquisa pode estar separado dos objetivos da pesquisa em si, objetivado fora desta? De fato, esse parece ser um caso frequente: o pesquisador empenha-se em oferecer algum tipo de retorno que não apenas retribua a hospitalidade e a colaboração dos nativos, mas sobretudo que justifique uma pesquisa cujos objetos próprios estão sob suspeita.

Há um ativo debate (Venkatesan, 2008; Viveiros de Castro, 2003) sobre a possibilidade de reontologizar a disciplina, na contracorrente dessa epistemologização iniciada séculos atrás e que culminou no relativismo e na crítica pós-moderna: a noção de que apenas podemos dar lugar a interpretaçóes da realidade, ficando sempre à margem desta. O objetivo dessa reontologização da antropologia não é fácil de resumir, mas deve incluir em algum momento uma discussão sobre a realidade do que ela produz, sobre uma pesquisa que não é mais apenas interpretativa, mas produtiva. Essa proposta tropeça no mesmo sofisma que alguma vez denunciou o programa forte dos estudos sobre a ciência: temos consciência da produtividade das ciências humanas, ou da antropologia em particular, na medida em que elas erraram, ética e epistemologicamente, por exemplo, na sua inserção no colonialismo, na fundamentação de regimes racistas ou no desenho da estrutura do apartheid sul-africano. Mas pouco nos detemos em considerar o papel criativo da antropologia nos projetos que ainda temos como válidos. ${ }^{12}$

Examinemos essa questão a partir de um bom exemplo. La chute du ciel, paroles d'un chamane Yanomami, assinado por Davi Kopenawa e Bruce Albert, poderia ser uma demonstração eminente de autoria compartilhada. Mas dizer isso é recorrer à inércia léxica. Na verdade, La chute du ciel é um duplo exercício de autoridade etnográfica, no velho sentido indiferenciado da auctoritas latina. Ou seja, é impossível descrever essa obra em termos da autoria em sentido estrito. Impossível separar, nesse livro extraordinariamente extenso, o que se deve a Kopenawa, aos espíritos em cujos ensinamentos se inspira, aos saberes do seu sogro ou dos outros xamãs que o instruíram; aos variados interlocutores brasileiros ou europeus com os quais perfilou suas ideias, aos missionários dos que tomou um vasto e vago acervo de noçôes teológicas; ao tradutor, Bruce Albert, que também escreve originalmente boa parte do milhar de páginas, e que, sorteando o abismo existente entre o vernáculo de Kopenawa e o francês do livro, teve literalmente que inventar um francês plausível para um intelectual yanomami - que não podia soar como um intelectual francês nem como um exótico iletrado. Quando Kopenawa e Albert, em momentos diferentes do livro, tentam a tarefa impossível de descrever o processo de elaboração do 
trabalho e de deixar claras as diversas feições de sua autoria, reconhecendo tantas outras contribuições, o que de fato fazem é afirmar a autoridade dos dois autores que assinam. São suas biografias - a dilatada colaboração entre ambos, por exemplo -que lhes dão a possibilidade de realizar uma obra que, enfim, não é uma visão ou uma interpretação da cultura Yanomami ou do encontro entre índios e brancos: tudo o que de visão e interpretação exista está integrado num objeto novo, com peso específico dentro dessa cultura yanomami ou dentro desse encontro interétnico. Reconhecendo as múltiplas contribuições de toda uma galáxia de coautores impossível de enumerar, Kopenawa e Albert acabam, na verdade, fugindo a esses deveres, impossíveis ou castradores, da autoria entendida como figura do direito autoral: a citação exata, a fidelidade aos enunciados originais, a delimitação das inspirações. Trata-se de uma tradução que assume suas traições e sua criatividade.

Sobretudo, trata-se de um objeto novo: no caso, um saber indígena global, que se coloca com maior ou menor sucesso na arena das discussōes sobre o destino do planeta e cujo valor depende dessa situação e não de sua fidelidade às fontes locais de inspiração. Um trabalho como o de Kopenawa e Albert não está diretamente interessado na preservação de um patrimônio e na reivindicação de sua autoria, mas na atualização de uma outra voz no cenário global. Toda pesquisa etnográfica, embora em geral não alcance o brilhantismo desta, tende sempre à mesma consequência: transforma, cria - uma capacidade que a tradição positivista lhe ensinou a ignorar. É o caso que ocupou boa parte deste artigo, dos projetos de resgate e afirmação da "cultura", como poderia ser o caso de qualquer outro projeto de pesquisa. Com certeza, suas consequências se completam somente no longo prazo, e são em certa medida imprevisíveis: mas uma parte relevante delas já está presente ali, nas mãos do pesquisador no momento em que cumpre com sua tarefa. Ele sabe já como a cumpriu, com quais recursos e com quais consequências imediatas; a crítica pós-moderna lhe ensinou a levar em conta suas condições subjetivas e a continuar ignorando seus resultados objetivos. Admite a realidade das relações que estabelece, mas não a eficiência destas.
A questão é que essa capacidade, costumeiramente recluída num ângulo cego, altera em muito os dilemas éticos ou políticos de qualquer pesquisa. Enquanto a produtividade da pesquisa - ou seja, a manifestação da sua auctoritas - não seja mais perceptível do que agora é, as discussões sobre autoridade e autoria não passarão de sucedâneos secundários.

\section{Notas}

1 Benveniste anota sua preocupação com o significado original de augeo, pois intui que esse significado de "fazer crescer" é tardio; ele supõe um significado primitivo de augeo que denote um "fazer nascer", uma produção original a partir do nada. Acaba encontrando esse sentido em Lucrécio - De rerum naturae - que não é precisamente uma fonte arcaica. Cabe a possibilidade de que essa criação a partir do nada que ele reputa primordial seja, na verdade, a mais tardia, uma contribuição do cristianismo.

2 O uso de exemplos espanhóis não é apenas um viés devido à cultura de origem do autor. A Espanha do final do século XV e inícios do XVI foi um laboratório para o desenvolvimento do Estado moderno e de algumas de suas armas principais. Antonio de Nebrija foi um dos seus agentes principais, com sua incisiva percepção do sentido político da língua e da gramática, e também da imprensa e do direito autoral.

3 Os Yaminawa (há outras grafias, como Jaminauá ou Yaminahua) são um povo de língua Pano, situado em numerosas aldeias do Brasil, Peru e Bolívia, sempre na bacia do Juruá-Purús. Cultural e linguisticamente muito próximos de outros povos "interfluviais" como os conhecidos pelo mesmo sufixo "nawa" (Yawa, Shara etc.) e - embora essa seja uma ideia menos canônica dos Shipibo do Ucayali. No Brasil existem cerca de quinhentos indivíduos, semelhante ao número de países vizinhos. Minha experiência entre eles, à qual me refiro neste artigo, remonta a 1993.

4 De fato, quando numa das minhas viagens à cidade lhe perguntei o que desejava que lhe trouxesse de lá, pediu-me uma mala - o que me surpreendeu, porque as malas se adaptam muito mal ao estilo das viagens yaminawa. Tempo depois, pude perceber que essas malas não serviam para viajar, mas para guardar sob chave itens privados, entre os quais as fotografias que eu distribuía amplamente e que os velhos gostavam de acumular. 
5 Essa disposição não é de modo algum geral, na mesma região ou no mesmo grupo linguístico: em muitos outros casos, a matéria mítica está sujeita a algum tipo de controle, ou, mesmo na ausência de interdições explícitas, a maior parte dos sujeitos declaram sua ignorância ou sua incapacidade de relatar.

6 Aplico aqui o reexame do binômio cultura versus "cultura" sugerido por Coelho de Souza (2010).

7 Tão pouco que a primeira redação deste artigo o negava. Fiquei sabendo, no entanto - por Fátima Ferreira, aluna de graduação da UFSC que realiza pesquisas entre eles - que alguns setores dos Yaminawa estão investindo fortemente no "resgate cultural". Minha descrição pode tornar-se logo um registro arqueológico de uma situação já transformada.

8 Estas consideraçōes se acrescentam às que Carneiro da Cunha (2009), Wiik (2010), Andrello (2012) ou Martini (2012), entre muitos outros, fazem a respeito dessa "cultura" vista não mais como elemento da política multiculturalista, mas como parte da interação com parentes ou espíritos. Wiik e Martini, em particular, referem-se à sensação de perigo decorrente de colocar de novo em circulação dentro da aldeia essa "cultura", rituais ou objetos sagrados já mortos, ou já incontroláveis na falta dos especialistas adequados.

9 Desenvolver este ponto exigiria um outro artigo: refiro-me a que, cancelado (em sua maior parte) o prestígio que se atribuía à objetividade científica (definida por uma legalidade epistemológica), seu lugar é disputado de um lado pela resubjetivação (por exemplo, a qualidade ética ou política da pesquisa) e de outro por uma tecnologia da objetivação, não mais epistemológica, feita de qualis, índices de impacto, estatísticas de citação etc. Embora opostas, ambas as tendências não parecem entrar em conflito.

10 "Proprietário" não faz parte, neste caso, da série proletário-mandatário etc., mas da série autoritário-libertário etc.; aparece frequentemente no relatório com esse matiz de doutrina ou de expectativa mais que de exercício. O relatório usa também a expressão "fazendeiros do ar" para se referir a um tipo de expectativa de lucros desmedidos - é o caso dos famosos 300 milhōes de dólares que suporia cada fármaco descoberto a partir do saber nativo - que tem sido difundida irresponsavelmente como argumento de muitos projetos e como virtual garantia do seu fracasso.

11 Não se abordará aqui se esses projetos têm as virtualidades econômicas em nome das quais é postulada a proteção e a retribuição dos direitos autorais indígenas, com independência de tradições e traduções; ou seja, se eles podem efetivamente beneficiar as $\mathrm{co}^{-}$ munidades. Para tratar disso seria necessário começar por um exame do papel que essas normas têm no mundo global, o que não caberia no espaço restrito deste artigo.

12 Confirmando a regra, esse papel é reconhecido, por exemplo, pelos críticos do multiculturalismo, para os quais esse projeto aparece já como nocivo ou ultrapassado.

\section{BIBLIOGRAFIA}

ANDRELLO, Geraldo. (2010), "Falas, objetos e corpos: autores indígenas no alto rio Negro". Revista Brasileira de Ciências Sociais, 25 (73): 5-26.

. (2012), "Histórias tariano e tukano: política e ritual no rio Uaupés". Revista de Antropologia, 55 (1): 291-330.

BENVENISTE, Émile. (1995), O vocabulário das instituiçôes indo-europeias. Campinas, Editora da Unicamp, vol. 2.

BROWN, Michael. (1998), "Can culture be copyrighted?”. Current Anthropology, 39 (2): 193-222.

CALAVIA SÁEZ, Oscar. (2006), O nome e o tempo dos Yaminawa. São Paulo, Editora da Unesp.

CALAVIA SÁEZ, Oscar; Cfarid Naveira, Miguel \& Pérez Gil, Laura. (2003), "O saber é estranho e amargo: sociologia e mitologia do conhecimento entre os Yaminawa”. Campos, 4: 9-28.

CARNEIRO DA CUNHA, Manuela. (2009), "CCultura' e cultura: conhecimentos tradicionais e direitos intelectuais", in Cultura com aspas, São Paulo, Cosac Naify, pp. 311-373.

CLIFFORD, James \& MARCUS, George E. (1986), Writing culture: the poetics and politics of ethnography. Berkeley, University of California Press.

COELHO DE SOUZA, Marcela. (2010), "A vida material das coisas intangíveis", in Marcela Coelho de Souza e Edilene Coffaci de Lima, Conhecimento e cultura: práticas de transformação do mundo indígena, Brasília, Athalaia, pp. 97-118. 
COVARRUBIAS, Sebastián de. (1611), Tesoro de la lengua castellana o española. Disponível em <http://bib.cervantesvirtual.com/servlet/ SirveObras/80250529545703831976613/ ima0351.htm>.

GEERTZ, Clifford. (1973), The interpretation of cultures: selected essays. Nova York, Basic.

GONÇALVES, Claudia Pereira. (2012), Divino Tserewahú. Video nas Aldeias et al.: uma etnografia de encontros intersocietários. Florianópolis, tese de doutorado, PPGAS, Universidade Federal de Santa Catarina.

INSTITUTO SOCIOAMBIENTAL. (2009), "Inovar para avançar: propondo novas formas de salvaguarda aos direitos intelectuais coletivos dos povos indígenas”. Relatório final para a Fundação Ford (mimeo.).

KOPENAWA, Davi \& Albert, Bruce. (2010), La chute du ciel: paroles d'un chaman Yanomami. Paris, Plon.

MARTINI, André. (2012), "O retorno dos mortos: apontamentos sobre a repatriação dos ornamentos de dança (basá busá) do Museu do Índio, em Manaus, para o Rio Negro”. Revista de Antropologia, 55 (1): 331-355.

NEBRIJA, Antonio de. (1494), Vocabulario español-latino. Disponível em <http://www. rae.es/Imagenes/textos/Biblioteca_Clasica/Archivos_de_Biblioteca_Clasica/ Nebrija_31_C_3686_280.pdf>.

STRATHERN, Marilyn. (1999), "What is intellectual property after?”, in J. Law e J. Hassard (eds.), Actor network theory and after, Oxford, Blackwell/The Sociological Review, pp. 156-180.

VENKATESAN, Soumhya (ed.). (2008), "Ontology is just another word for culture". Motion tabled at the 2008 meeting of the Group for Debates in Anthropological Theory (GDAT), University of Manchester.

VIVEIROS DE CASTRO, Eduardo. (2003), “And”. Manchester Papers in Social Anthropology, 7.

WAGNER, Roy. (2010), A invenção da cultura. São Paulo, Cosac Naify.

WIIK, Flavio Braune. (2010), "Somos índios crentes": dialéticas do contato, alteridade e mediação cultural entre os Xokleng (Jê) de Santa Catarina”. Tellus, 10 (19): 11-51. 


\section{A ÉTICA DA PESQUISA NA \\ ERA DA AUTORIA: DIREITO \\ INTELECTUAL INDÍGENA, SOCIALIDADE E INVENÇÃO ANTROPOLÓGICA}

\section{Oscar Calavia Sáez}

Palavras-chave: Autoria; Autoridade; Cultura; Yaminawa; Yanomami; Direitos intelectuais.

A ética na pesquisa antropológica está cada vez mais centrada, no Brasil, na autoria indígena - e, portanto, na propriedade intelectual. $\mathrm{O}$ nativo é um autor da cultura indígena, e direitos coletivos deveriam garantir essa propriedade. No entanto, os direitos intelectuais sempre foram a própria substância da relação social, a riqueza que passaria de uma geração a outra, ou entre afins. E foi, assim, um instrumento em mãos das autoridades locais, que tinham o poder de doar ou reter esse conhecimento. Os esforços atuais de atribuir esses direitos à comunidade, embora sejam vistos como uma tentativa de preservação cultural, incluem na verdade uma reforma social, construindo um conjunto de novas relaçôes, geridas por um conjunto de novos sujeitos políticos. Se os debates éticos hão de ser completos, a autoria do pesquisador deve ser contabilizada não apenas nas suas publicações, mas também nas inovações culturais que promove.

\section{ETHICS IN RESEARCH IN THE ERA OF AUTORSHIP: INDIGENOUS INTELLECTUAL RIGHTS, SOCIABILITY AND ANTHROPOLOGICAL INVENTION}

\section{Oscar Calavia Sáez}

Keywords: Authorship; Authority; Culture; Yaminawa; Yanomami; Intellectual rights.

Ethics in anthropological research in Brazil is increasingly focused on indigenous authorship -and, therefore, on intellectual property. The native is an author of the indigenous culture and science, and collective rights should be issued to warrant this property. However, intellectual rights used to be, prior to this trend, the very matter of social relationship, the wealth to be handled from one generation to another, or between in-laws. And was, thus, a tool for local authorities, which have the power of [donate or retain] donating or retaining it. Current efforts to entitle community with these rights, while putatively an essay of cultural safeguard, embody instead a social reform, building a set of new relationships, handled by a set of new political subjects. If ethical debates are to be thoroughly accomplished, the researcher's authorship must be reckoned not only in papers or books but also in the cultural innovations it promotes.

\section{L'ÉTHIQUE DE LA RECHERCHE À L'ÈRE DE LA PROPRIÉTÉ \\ INTELLECTUELLE: LE DROIT INDIGÈNE DE LA PROPRIÉTÉ INTELLECTUELLE, LA SOCIABILITÉ ET LINVENTION ANTHROPOLOGIQUE}

\section{Oscar Calavia Sáez}

Mots-clés: Propriété intellectuelle; Autorité; Culture; Yaminawa; Yanomami; Droits intellectuels.

Les enjeux éthiques de la recherche anthropologique au Brésil sont de plus en plus centrés sur la propriété intellectuelle de l'indigène. Le natif est un auteur de la culture indigène et des droits collectifs qui devraient garantir cette propriété Mais le droit à la propriété intellectuelle a toujours été l'essence même des rapports sociaux, de la richesse qui passerait d'une génération à l'autre, ou entre les individus d'une même génération. Il a, ainsi, été un instrument au service des autorités locales, qui avaient le pouvoir de donner ou de garder ce savoir. Les efforts actuels pour attribuer ces droits à la communauté, quoique considérés comme un essai de préservation culturelle, incluent, en vérité, une réforme sociale, en construisant un ensemble de nouveaux rapports, gérés par un ensemble de nouveaux sujets politiques. Si les débats étiques doivent être complets, la reconnaissance de la propriété intellectuelle du chercheur doit être reconnue non seulement grâce à ses publications, mais aussi par les innovations culturelles qu'il promeut. 